\title{
RESEARCH
}

Open Access

\section{Human cystic echinococcosis in southwest Iran: a 15-year retrospective epidemiological study of hospitalized cases}

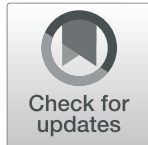

\author{
Reza Shahriarirad ${ }^{1,2}$, Amirhossein Erfani ${ }^{1,2}$, Mehrdad Eskandarisani ${ }^{1}$, Mohammad Rastegarian?
} Hajar Taghizadeh ${ }^{1}$ and Bahador Sarkari ${ }^{3,4^{*}}$ (i)

\begin{abstract}
Background: Cystic echinococcosis (CE) is considered as a neglected disease with significant mortality and morbidity in most of the developing countries. The current study aimed to retrospectively assess the demographic and epidemiologic features of human CE surgical cases in a 15-year period in Fars province, southwestern Iran.

Methods: A 15-year (2004-2018) retrospective study was conducted to find out the epidemiological and clinical picture of CE in patients who undergone surgeries for CE in two main hospitals in Fars Province, southwestern Iran. Hospital records were reviewed, and data were retrieved from each CE patient's record.

Results: A total of 501 CE surgical cases were recorded during a 15-year period, corresponding to an average annual incidence of 33.4 and a surgical incidence rate of $0.74 / 100,000$ population. Of these, $242(48.6 \%)$ were male, and $256(52.4 \%)$ were female. Patients' age ranged from 2 to 96 years, with a mean age of $34.92( \pm 19.87)$ years. A significantly higher rate of CE cases was noted in subject's $\geq 50$ years of age. The highest frequency of cases (62: 12.5\%) was recorded in the year 2017. The most commonly involved organs were liver (339 cases; $57.8 \%$ ) and lung (279 cases; $47.6 \%)$. Concurrent involvement of two organs was seen in 58 (9.9\%) cases of both lung and liver, 10 (1.6\%) cases of lung and other locations (but not liver), and 23 (3.9\%) cases of liver and other locations (but not lung). Reoperation was noted in 67 (13.4\%) of the cases. The size of the lung hydatid cyst varied, ranging between 2 and $24 \mathrm{~cm}$ (mean $=7.33, \mathrm{SD}=3.737$ ). The size of liver hydatid cysts ranged from 1 to $26 \mathrm{~cm}$ (mean 9.04, SD = 4.275).

Conclusion: The findings of the current study demonstrated a nearly constant prevalence of CE during the last 15 years in southern Iran. Further studies are needed to find out the reasons behind the recurrence of the disease, which is substantial, in surgically-treated patients.
\end{abstract}

Keywords: Cystic echinococcosis, Hospital record, Fars prevalence, Southwestern Iran

\footnotetext{
*Correspondence: sarkarib@sums.ac.ir

${ }^{3}$ Department of Parasitology and Mycology, School of Medicine, Shiraz

University of Medical Sciences, Shiraz, Iran

${ }^{4}$ Basic Sciences in Infectious Diseases Research Center, Shiraz University of

Medical Sciences, Shiraz, Iran

Full list of author information is available at the end of the article
}

(c) The Author(s). 2020 Open Access This article is licensed under a Creative Commons Attribution 4.0 International License, which permits use, sharing, adaptation, distribution and reproduction in any medium or format, as long as you give appropriate credit to the original author(s) and the source, provide a link to the Creative Commons licence, and indicate if changes were made. The images or other third party material in this article are included in the article's Creative Commons licence, unless indicated otherwise in a credit line to the material. If material is not included in the article's Creative Commons licence and your intended use is not permitted by statutory regulation or exceeds the permitted use, you will need to obtain permission directly from the copyright holder. To view a copy of this licence, visit http://creativecommons.org/licenses/by/4.0/. 


\section{Background}

Cystic echinococcosis (CE), due to Echinococcus granulosus, is one of the most significant zoonotic diseases, throughout most parts of the world [1]. Herbivores such as sheep, goats, and swine are intermediate hosts of $E$. granulosus, which become infected by eating the worm eggs passed in the carnivores' feces. Carnivores, as definitive hosts, ingest the cyst-containing organs of herbivores and harbor worms in their digestive system [2]. Humans become infected via ingesting embryonated eggs through hands, water, or food contaminated with parasite eggs that passed through the feces of definitive hosts. The oncospheres spread through blood and lymphatic circulation to the liver, the lungs, and other organs, where the development of the Echinococcus cysts occurs.

Cystic echinococcosis is asymptomatic at the early phases of the infection; however, it becomes symptomatic when the cysts become larger or complicated. Clinical manifestations of CE vary based on the size, location, and condition of the cystic structure [3].

$\mathrm{CE}$ is considered a neglected disease with significant mortality and morbidity in most of the developing countries $[1,4,5]$. The disease is a major health and economic challenges in the Middle East countries, including Iran where about $1 \%$ of all hospital surgeries are accounted for this disease [1, 4, 5]. A recent systematic review and meta-analysis reported the overall seroprevalence of CE in Iran to be $4.2 \%$ in human hosts, with the highest seroprevalence $(5.8 \%)$ in the South and the least $(2.2 \%)$ in the central areas of the country [6].

$\mathrm{CE}$ is more frequently occurring in rural and nomadic communities where people have continuous contact with dogs, the definitive host of E. granulosus. Studies in both West and East Azerbaijan and Hamedan provinces in Iran demonstrated that rural residents constitute the most common referral cases of CE [7-9].

$\mathrm{CE}$ is one of the most important parasitic diseases in Fars province in the southwest of Iran $[5,10]$. Fars province is the center of agriculture and animal husbandry in Iran and one of the most important and populated tribal nomads (Qashqai) resides in this area. The burden and incidence of CE which are the basis for the development of appropriate control programs are poorly known in Fars province, in southwestern Iran. Hence, the current study was designed and conducted to assess the demographic and epidemiological features of CE during a 15year period in the south of Iran, based on the hospital records.

\section{Methods}

\section{Study area}

This study was conducted in Fars Province in southwestern Iran. The district is located at an altitude of $1545 \mathrm{~m}$ above the sea level at geographical coordinates of $29^{\circ}$ $36^{\prime} 37^{\prime \prime} \mathrm{N}$ latitude and $52^{\circ} 31^{\prime} 52^{\prime \prime}$ E longitudes. The area has a hot summer and moderate winter. Agriculture has always been a major part of the economy in Fars province. The province has a population of 4.6 million.

\section{Data collection}

In this retrospective study, hospital records of $\mathrm{CE}$ patients were reviewed, and data were retrieved for a 15year period, from 2004 to 2018 at the main universityaffiliated and referral hospitals (Nemazi and Shahid Faghihi) in Shiraz, capital of Fars Province.

Hydatid cyst diagnosis was based on histopathological confirmation after the surgery. Moreover, those patients in which the CE was initially diagnosed by imaging findings and confirmed at surgery, and those with negative histopathological findings (although rare), but characteristic imaging findings and with a positive serology test (mainly CCIEP: Counter Current Immunoelectrophoresis) were considered and recorded as CE cases.

Only cases with a final diagnosis of any type of $\mathrm{CE}$ at hospital discharge which were recorded with a unique disease code (based on the ICD-9 and ICD-10: International Classification of Diseases; 122.9 , and 122.8 for ICD9; B67.8, K77.0, B67.9, and J99.8 for ICD10) were included in the data analysis. Suspected cases were not included in the study.

From each patients' hospital record, demographical data (age, sex, place of residence, etc.), history of the previous $\mathrm{CE}$, hydatid cyst features (size, location, multiple organ involvement), treatment measurement (the type of surgery, drug therapy, recurrence), and duration of hospital stay were collected in a data sheet.

The hospital records for a few years of the study were not available in the hospital database. Therefore, the medical records were searched manually by members of the research team which consisted of physicians as well as medical students.

\section{Statistical analysis}

All the statistical analyses were performed by using statistical package for social sciences (SPSS Inc., Chicago, Illinois, USA) version 22.0. A descriptive analysis was performed on the demographics characteristics. Categorical and continuous data were reported as proportions and means \pm SDs. Chi-square or Fisher's exact test was used to test the differences between the categorical variables.

\section{Results}

A total of $501 \mathrm{CE}$ surgical cases were diagnosed and underwent surgery in two main hospitals in the 15-year period from 2004 to 2018, giving an average annual incidence of 33.4 cases and an annual incidence rate of 0.74 


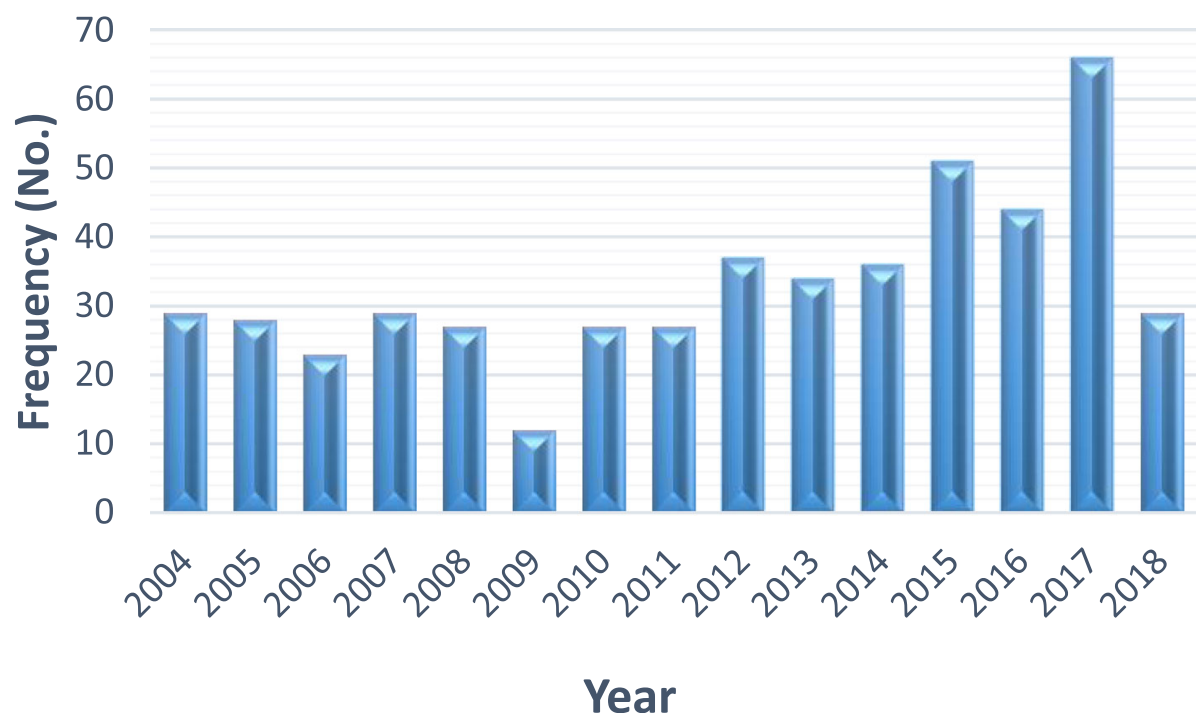

Fig. 1 Frequency of CE cases per year, during 2004-2018 in Fars province, southwest Iran

per 100,000 population. The mean age of the patients was $34.92( \pm 19.87)$ years. The youngest patient was a 2year-old girl, and the oldest one was a 96-year-old man. Of the total number of patients, $26 \%$ were $\geq 50$ years old. Out of $501 \mathrm{CE}$ cases, 242 (48.6\%) were male while $256(51.4 \%)$ were female. Furthermore, based on the gender of the patients, the median age of male cases was
30 years [IQR $14-48]$, $($ mean $=32.79, \mathrm{SD}=20.37)$, while for female, the median was 35 years [IQR 22-53] (mean $=36.77, \mathrm{SD}=19.31)$. The highest frequency of cases $(62$, 12.5\%) was recorded in the year 2017. Figure 1 shows the frequency of $\mathrm{CE}$ cases, per year in the current study.

Considering the residential areas of the patients, the majority of cases (76\%) originating from Fars Province,

Table 1 location of hydatid cysts in CE cases in southwestern Iran, based on hospital record, during a 15-year period (2004-2018)

\begin{tabular}{|c|c|c|}
\hline Location & Frequency (No.) & Percent (\%) \\
\hline Lung & 279 & 47.6 \\
\hline Liver & 339 & 57.8 \\
\hline Spleen & 14 & 2.4 \\
\hline Pelvic cavity & 7 & 1.2 \\
\hline Heart & 4 & 0.7 \\
\hline Sub diaphragm & 5 & 0.9 \\
\hline Abdominal and peritoneal cavity & 5 & 0.9 \\
\hline Other locations ${ }^{*}$, ** & 12 & 2 \\
\hline Lung and liver & 58 & 9.9 \\
\hline Lung and spleen & 2 & 0.3 \\
\hline Lung and pelvic cavity & 1 & 0.2 \\
\hline Lung and sub diaphragm & 2 & 0.3 \\
\hline Lung and heart & 2 & 0.3 \\
\hline Lung and other locations ${ }^{*}$ & 3 & 0.5 \\
\hline Liver and spleen & 6 & 1 \\
\hline Liver and pelvic cavity & 6 & 1 \\
\hline Liver and sub diaphragm & 3 & 0.5 \\
\hline Liver and abdominal and peritoneal cavity & 3 & 0.5 \\
\hline Liver and other locations ${ }^{* *}$ & 5 & 0.9 \\
\hline Spleen and pelvic cavity & 1 & 0.2 \\
\hline
\end{tabular}

*Common bile duct, mediastina, pancreas, **Kidney, mediastinum, mesothelium of the terminal ileum, pancreas, psoas muscle 
whereas cases from neighboring Provinces mainly Kohgiluyeh and Boyer-Ahmad (7\%) and Bushehr (4.4\%), were also among the patients.

The median duration of hospital stay for patients was 7.5 days [IQR 5-13]. The most commonly involved organs were liver (339 cases; $57.8 \%$ ), and lung (279 cases; $47.6 \%$ ). Also, 46 (7.8\%) cases had hydatid cyst in other locations including spleen, heart, and diaphragm. Among the lung hydatid cyst cases, 126 (64.9\%) were located in the right lung while 103 (59.5\%) were located in the left lung. Also, regarding the liver hydatid cysts, 193 (47.1\%) of cases had cyst in the right lobe while 76 (18.9\%) had cyst in the left lobe. Concurrent involvement of two organs was seen in 58 (9.9\%) cases of both lung and liver, 10 (1.7\%) cases of lung and other locations (excluding liver), and 22 (3.8\%) cases of liver and other locations (excluding lung). Table 1 shows the location of hydatid cyst in CE cases in southwest Iran.

Multiple organ involvements of lung, liver, and spleen were seen in $2(0.3 \%)$ cases, lung, liver and pelvic cavity in $1(0.2 \%)$ case, lung liver, and sub-diaphragm in $1(0.2 \%)$ case, and lung, liver, and pancreas in $1(0.2 \%)$ case.

Secondary hydatid cyst or relapse was seen in 67 $(13.37 \%)$ of the patients, in which the secondary cysts in 28 (41.8\%) were lung cysts, 42 (62.7\%) were liver cyst, 1 (1.5\%) was pelvic cyst, 1 (1.5\%) was spleen cyst, 1 (1.5\%) was abdominal and peritoneal cavity, and $1(1.5 \%)$ was in the mesothelium of the terminal ileum. It is worth mentioning that 11 of the cases underwent surgery due to tertiary hydatid cyst or relapse for the third time and also 3 of the cases underwent a fourth surgery due to hydatid cyst. Table 2 shows the demographic features of the CE patients along with the cyst features.

From the 279 cases of lung hydatid cyst, the majority (174: 74\%) had a single cyst while 46 (19.6\%) cases had two, and $15(6.4 \%)$ cases had three or more cysts. It is worth knowing that from the 279 cases of lung hydatid cyst, 157 (56.3\%) cases were male while 120 (43.3\%) were female. There was a significant correlation between lung hydatid cysts and the patients' gender $(P<0.001)$. The size of the lung hydatid cyst varied, ranging between 2 and $24 \mathrm{~cm}$ (mean $=7.33, \mathrm{SD}=3.737)$ with the highest frequency $(175,96.2 \%)$ of the largest diameter of the cyst being in group 11 to $15 \mathrm{~cm}$. The lung cyst area ranging from 2 to $490 \mathrm{~cm}^{2}$ (mean 42.27, $\mathrm{SD}=50.061$ ) with the majority in under $26 \mathrm{~cm}^{2}$ group (83:48.3\%).

In our study, among the 339 cases of liver hydatid cyst, 194 (68.1\%) had single cysts, 56 (19.6\%) had two cysts, and $35(12.3 \%)$ had three or more cysts. The size of liver hydatid cysts ranged from 1 to $26 \mathrm{~cm}$ (mean 9.04, SD = 4.275 ) with the highest frequency of the largest diameter of the cyst being in group 6 to $10 \mathrm{~cm}$. The area square centimeters of the liver cyst ranged from 1 to $392 \mathrm{~cm}^{2}$ $($ mean $=58.43, \mathrm{SD}=52.556)$ with the majority $(82$ : $31.9 \%$ ) in under $26 \mathrm{~cm}^{2}$ group.
Table 2 Demographic features of the CE patients along with the cyst characteristics

\begin{tabular}{|c|c|c|}
\hline Characteristics & Frequency (No.) & Percent (\%) \\
\hline \multicolumn{3}{|l|}{ Gender } \\
\hline Male & 245 & 49.1 \\
\hline Female & 254 & 50.9 \\
\hline \multicolumn{3}{|l|}{ Province } \\
\hline Fars & 380 & 75.7 \\
\hline Kohgiluyeh and Boyer-Ahmad & 37 & 7.4 \\
\hline Bushehr & 23 & 4.6 \\
\hline Khuzestan & 14 & 2.8 \\
\hline Foreign countries & 6 & 1.2 \\
\hline Sistan and Balochistan & 4 & 0.8 \\
\hline Kerman & 3 & 0.6 \\
\hline Kermanshah & 2 & 0.4 \\
\hline Khorasan Razavi & 2 & 0.4 \\
\hline Other Provinces ${ }^{1}$ & 7 & 1.4 \\
\hline \multicolumn{3}{|l|}{ Age groups (years) } \\
\hline$<10$ & 51 & 10.2 \\
\hline $10-19$ & 70 & 14.1 \\
\hline $20-29$ & 98 & 19.7 \\
\hline $30-39$ & 94 & 18.9 \\
\hline $40-49$ & 55 & 11 \\
\hline$>50$ & 130 & 26.1 \\
\hline \multicolumn{3}{|l|}{ Number of cysts } \\
\hline Single & 343 & 69.6 \\
\hline Two cysts & 98 & 19.9 \\
\hline Three cysts & 23 & 4.7 \\
\hline Four cysts & 8 & 1.6 \\
\hline Five or more cysts & 21 & 4.3 \\
\hline \multicolumn{3}{|l|}{ Size of cysts (cm) } \\
\hline$=<5 \mathrm{~cm}$ & 69 & 14.1 \\
\hline $6-10$ & 164 & 33.6 \\
\hline $11-15$ & 232 & 47.5 \\
\hline$>=16$ & 23 & 4.7 \\
\hline \multicolumn{3}{|l|}{ Area of the cyst $\left(\mathrm{cm}^{2}\right)$} \\
\hline$=<25$ & 179 & 38.7 \\
\hline $26-50$ & 112 & 24.2 \\
\hline $51-75$ & 48 & 10.4 \\
\hline $76-100$ & 62 & 13.4 \\
\hline$>=100$ & 61 & 13.2 \\
\hline
\end{tabular}

'Other Provinces: Zanjan, Qom, Lorestan, Isfahan, Ilam, Hormozgan, East Azerbaijan

In other locations, apart from the lung and liver, the numbers of cysts varied were $21(3.6 \%)$ cases had only a single cyst, 7 (1.2\%) cases had two cysts, and $8(1.4 \%)$ cases had three or more. The size of the cysts varied, 
ranging between 2 and $18 \mathrm{~cm}($ mean $=8.73, \mathrm{SD}=4.527)$ with the highest frequency (19: 55.9\%) being in the 6 to $10 \mathrm{~cm}$ group. The area square centimeters of the cysts in other locations ranged between 3 and $314 \mathrm{~cm}^{2}$ (mean = $59.14, \mathrm{SD}=64.287)$. Based on the surgical intervention for the patients, $142(28.3 \%)$ underwent radical surgery while 360 (71.9\%) underwent conservative surgery. Regarding the medications administered for the patients, 284 (56.6\%) patients received anti-helminthic drugs, including albendazole in $282(56.2 \%)$ and mebendazole in $5(1 \%)$ cases.

\section{Discussion}

$\mathrm{CE}$ is a zoonotic parasitic infection that occurs all over the world and causes substantial public health problems and economic losses. The Middle East is considered as the hot spot of CE in the world [1, 10]. CE is endemic and highly prevalent in Iran where human cases have been reported from nearly every province in the country $[5,10-12]$. The incidence rate of $C E$ in Iran has been reported to be $1.3-3 / 100,000$ population. Our study demonstrated a surgical incidence of $0.74 / 100,000$ inhabitants for $\mathrm{CE}$ in southern Iran. It should be noted that the 1.3-3/100,000 incidence of CE has been considered for all CE cases in Iran while our study only included cases that underwent surgery. This means that the total numbers of admitted cases (both surgical and non-surgical cases) in our center could be higher.

A higher rate of CE incidence (4.5 cases/100,000/year) has been reported in neighboring Iraq [13]. An incidence of 0.87 to 6.6 per 100,000 inhabitants has been reported for $C E$ in Turkey [14]. A retrospective analysis of CE in Aydın Adnan Menderes University training and research hospital in Turkey, from 2005 to 2017, reported 247 pathologically confirmed cases [15]. In Pakistan, data regarding human $\mathrm{CE}$ is limited [16]. A retrospective study of hospital records from five major metropolitan cities of Pakistan reported 188 surgically confirmed cases of CE corresponding to an annual frequency of 18.8 cases/year [17]. Another retrospective study in Northeastern Punjab Province reported a total of 198 cases of CE during a 6-year period (2012-2017) [18].

Although cases of $\mathrm{CE}$ are being reported from all the 31 provinces of Iran, the disease is more prevalent in sheep-breeding areas, including Fars province in the south of the country. The present study describes a detailed status of the geographical distribution as well as the epidemiological features of $\mathrm{CE}$ in southern Iran through retrospective reviewing of the patients' hospital records during a 15-year period. The annual surgical cases of CE were found to be 33.5 cases. It should be noted that some of the CE patients may seek treatment in local hospitals, where sufficient equipment are available for $\mathrm{CE}$ operation. It is also worth mentioning that there is a tendency by most surgeons to manage the $\mathrm{CE}$ by using a kind of "watch and wait" policy or chemotherapy instead of surgery and only the complicated cases undergoing operations. This again results in a decreased number of patients who undergo surgeries and decrease the number of $\mathrm{CE}$ hospital records. With these in mind, the actual annual prevalence rate of $\mathrm{CE}$ would be higher in the study area.

$\mathrm{CE}$ is reported to have a higher prevalence rate in women than in men in Iran which can be due to the household activities of women that are traditionally a part of their daily routine life $[7,19]$. This finding is in line with our previous study and also a retrospective hospital-based study by Abdulhameed in Basrah, Iraq, a neighboring country to Iran, where females were reported to be the main victims of CE $[13,20]$. Previous studies suggested that women have the highest chance of contact with sources of infection such as dogs, soil, and vegetable [5, 21, 22]. Housewives, particularly in rural areas, where the disease is more prevalent, have the highest chance of contact with the sources of infection. However, in studies of Cohen et al. [23] and Qaqish et al. [24], such associations were not observed.

In this regard, a meta-analysis by Khalkhali et al. on the prevalence of hydatid cysts in Iran found that although the rate of infection with hydatid cysts was higher in females than males, the difference was not statistically significant [6]. Thus, in some areas, a greater frequency of CE in males may be seen [25-27].

In our study, the majority of $C E$ cases were $\geq 50$ years old. This is mainly because $\mathrm{CE}$ is a slow-growing cyst in humans and usually presents the signs and symptoms at a higher age of life, whereas the infection may occur in younger people or even teenagers. The fact that all age groups, including children and young adults, were well represented in the confirmed $\mathrm{CE}$ cases and suggest that both adults and children are susceptible to infection, as previously documented $[5,28]$. In accordance with the available evidence, $\mathrm{CE}$ in Iran has no privilege for age. In a study by Moldovan et al., a total of $190 \mathrm{CE}$ cases in two counties of Romania were reviewed and revealed the highest rate of infection in 60-69 years old patients [29].

$\mathrm{CE}$ is not uncommon in young children as 51 (10.16\%) of cases in our study were children under 10 years old. In line with our findings, a retrospective study regarding $\mathrm{CE}$ cases in children in one of the hospitals in the south of Iran reported 57 children with CE during a 12-year period, 2003-2014 [28].

Findings of the present study further documented that hydatid cyst occurs predominantly in the liver and lung and occasionally in the heart, spleen, abdomen, and pelvis. Moreover, the lungs are predominantly infected with hydatid cyst other than any organ possibly due to the presence of greater capillary beds in the lungs in comparison with other organs [30-32]. 
In the present study, data about the WHO ultrasound classification of the hydatid cysts were not available in the patients' hospital records. Such data are very important for management as well as follow-up of patients. With the establishment of a regular registration system, such information would be included by radiologists to the patients' hospital records.

The retrospective hospital surveys have been generally criticized for not providing precise estimates of the disease incidence as not all hospitals in a particular region or district are included in the study. Besides, retrospective hospital survey data on human CE cannot give an accurate picture of the prevalence of the infection. A certain number of cases are not observed in hospital records since the infection is asymptomatic or does not need surgical intervention. Besides, some data are not available in the hospital records. Yet, the hospital records can indicate the public health importance of the disease and, when done constantly over many years, can detect regional variations in the incidence of the infection [33]. More importantly, establishing a registered database for documenting cases of $\mathrm{CE}$ in endemic areas such as Iran is essential to reach a better understanding of the prevalence and extent of the disease. Such a system has recently been launched in a few provinces in Iran. Moreover, Iran and Turkey have recently joined the European Register of CE.

\section{Conclusion}

Taken together, findings of the current study revealed that human $\mathrm{CE}$ is a common infectious disease in the southwest of Iran with a relatively constant rate during the last 15-year period of evaluation. A health education program to increase awareness of how $\mathrm{CE}$ is transmitted, along with regular surveillance of the disease, would help to reduce the infection rate in this area of Iran. Moreover, the burden of disease in the investigated area would justify starting a well-organized control program as $\mathrm{CE}$ is a preventable disease.

\section{Acknowledgements}

The technical assistant of staff in Nemazi and Faghihi hospitals is acknowledged.

\section{Authors' contributions}

$B S$ and RS designed the study. RS, AE, ME, MR, and HT collected the data. BS, $R S, M R$, and $A E$ carried out the statistical analysis and helped with manuscript writing. RS and AE drafted the manuscript. BS revised and proofread the manuscript. All authors read and approved the final version of the manuscript.

\section{Funding}

The study was financially supported by the office of vice-chancellor for research of Shiraz University of Medical Sciences (Grant No. 94-01-01-9212).

\section{Availability of data and materials}

SPSS data of the participant can be requested from the authors. Please write to the corresponding author if you are interested in such data.

\section{Ethics approval and consent to participate}

The study was approved by the Ethics Committee of the Shiraz University of Medical Sciences. The patients' records were anonymized and de-identified prior to analysis. The confidentiality of the details of the subjects was assured.

\section{Consent for publication}

Not applicable.

\section{Competing interests}

The authors declare that they have no competing interests.

\section{Author details}

${ }^{1}$ Student Research Committee, Shiraz University of Medical Sciences, Shiraz, Iran. ${ }^{2}$ Thoracic and Vascular Surgery Research Center, Shiraz University of Medical Sciences, Shiraz, Iran. ${ }^{3}$ Department of Parasitology and Mycology, School of Medicine, Shiraz University of Medical Sciences, Shiraz, Iran. ${ }^{4}$ Basic Sciences in Infectious Diseases Research Center, Shiraz University of Medical Sciences, Shiraz, Iran.

Received: 17 April 2020 Accepted: 11 June 2020

Published online: 19 June 2020

\section{References}

1. Deplazes P, Rinaldi L, Alvarez Rojas CA, Torgerson PR, Harandi MF, Romig T, Antolova D, Schurer JM, Lahmar S, Cringoli G, et al. Global distribution of alveolar and cystic echinococcosis. Adv Parasitol. 2017;95:315-493.

2. Romig T, Deplazes P, Jenkins D, Giraudoux P, Massolo A, Craig PS, Wassermann M, Takahashi K, de la Rue M. Ecology and life cycle patterns of Echinococcus species. Adv Parasitol. 2017:95:213-314.

3. Kern P, Menezes da Silva A, Akhan O, Müllhaupt B, Vizcaychipi KA, Budke C, Vuitton DA. The echinococcoses: Diagnosis, clinical management and burden of disease. Adv Parasitol. 2017:96:259-369.

4. Fasihi Harandi M, Budke CM, Rostami S. The monetary burden of cystic echinococcosis in Iran. PLoS Negl Trop Dis. 2012;6(11):e1915.

5. Sarkari B, Arefkhah N, Ghorbani F, Meskini F, Yektaeian N, Shahriarirad S, Mostafavi-Pour Z. Seroprevalence of cystic echinococcosis and related risk factors for infection among children in a rural community in Fars Province, Southern Iran. Clin Epidemiol Global Health. 2020;8(1):13-6.

6. Khalkhali HR, Foroutan M, Khademvatan S, Majidiani H, Aryamand S, Khezri $P$, Aminpour A. Prevalence of cystic echinococcosis in Iran: a systematic review and meta-analysis. J Helminthol. 2018;92(3):260-8.

7. Ghabouli Mehrabani N, Kousha A, Khalili M, Mahami Oskouei M, Mohammadzadeh M, Alizadeh S, Maleksabet A, Hamidi F. Hydatid cyst surgeries in patients referred to hospitals in East Azerbaijan Province during 2009-2011. Iran J Parasitol. 2014:9(2):233-8.

8. Ahmadi N, Hamidi M. A retrospective analysis of human cystic echinococcosis in Hamedan province, an endemic region of Iran. Ann Trop Med Parasitol. 2008;102(7):603-9.

9. Hajipirloo HM, Bozorgomid A, Alinia T, Tappeh KH, Mahmodlou R. Human cystic echinococcosis in west azerbaijan, northwest iran: a retrospective hospital based survey from 2000 to 2009. Iran J Parasitol. 2013:8(2):323.

10. Sadjjadi SM. Present situation of echinococcosis in the Middle East and Arabic North Africa. Parasitol Int. 2006;55(Suppl):S197-202.

11. Rokni MB. Echinococcosis /hydatidosis in Iran. Iran J Parasitol. 2009:4:1-16.

12. McManus DP. Echinococcosis with particular reference to Southeast Asia. Adv Parasitol. 2010;72:267-303.

13. Abdulhameed MF, Habib I, Al-Azizz SA, Robertson I. A retrospective study of human cystic echinococcosis in Basrah province, Iraq. Acta Trop. 2018;178: 130-3.

14. Altintas N. Past to present: echinococcosis in Turkey. Acta Trop. 2003;85(2): $105-12$.

15. Ertabaklar H, Yıldız I, Malatyalı E, Tileklioğlu E, Çalışkan SÖ, Ertuğ S. Retrospective analysis of cystic echinococcosis results in Aydın Adnan Menderes university training and research hospital parasitology laboratory between 2005 and 2017. Turkiye Parazitol Derg. 2019 Sep 10:43(3):118-22.

16. Ahmed H, Ali S, Afzal MS, Khan AA, Raza H, Shah ZH, Simsek S. Why more research needs to be done on echinococcosis in Pakistan. Infect Dis Poverty. 2017:6(1):90.

17. Muqaddas H, Arshad M, Ahmed H, Mehmood N, Khan A, Simsek S. Retrospective study of cystic echinococcosis (ce) based on hospital record 
from five major metropolitan cities of Pakistan. Acta Parasitol. 2019;64(4): $866-72$.

18. Khan A, Zahoor S, Ahmed H, Malik U, Butt RA, Muzam MS, Kilinc SG, Noor N, Zahoor S, Afzal MS, Mansur H, Irum S, Simsek S. A retrospective analysis on the cystic echinococcosis cases occured in Northeastern Punjab Province, Pakistan. Korean J Parasitol. 2018;56(4):385-90.

19. Budke CM, Carabin H, Ndimubanzi PC, Nguyen H, Rainwater E, Dickey M, Bhattarai R, Zeziulin O, Qian M-B. A systematic review of the literature on cystic echinococcosis frequency worldwide and its associated clinical manifestations. Am J Trop Med Hyg. 2013;88(6):1011-27.

20. Sarkari B, Sadjjadi SM, Beheshtian MM, Aghaee M, Sedaghat F. Human cystic echinococcosis in Yasuj District in Southwest of Iran: an epidemiological study of seroprevalence and surgical cases over a ten-year period. Zoonoses Public Health. 2010;57(2):146-50.

21. Aboudaya M. Prevalence of human hydatidosis in Tripoli region of Libya. Int J Zoonoses. 1985;12(4):304-7.

22. O'leary P. A five-year review of human hydatid cyst disease in Turkana District, Kenya. East Afr Med J. 1976;53(9):540-4.

23. Cohen H, Paolillo E, Bonifacino R, Botta B, Parada L, Cabrera P, Snowden K, Gasser R, Tessier R, Dibarboure L. Human cystic echinococcosis in a Uruguayan community: a sonographic, serologic, and epidemiologic study. Am J Trop Med Hyg. 1998;59(4):620-7.

24. Qaqish A, Nasrieh M, Al-Qaoud K, Craig P, Abdel-Hafez S. The seroprevalences of cystic echinococcosis, and the associated risk factors, in rural-agricultural, bedouin and semi-bedouin communities in Jordan. Ann Trop Med Parasitol. 2003;97(5):511-20.

25. Mamishi S, Sagheb S, Pourakbari B. Hydatid disease in Iranian children. J Microbiol Immunol Infect. 2007;40(5):428.

26. Sadeghian H, Sian N. Hydatid cyst in Children. Pejuhandeh. 2000;1 (5):359-64.

27. Kandeel A, Ahmed E, Helmy H, El Setouhy M, Craig P, Ramzy R. A retrospective hospital study of human cystic echinococcosis in Egypt. East Mediterr Health J. 2004;10(3):349-57.

28. Sanaei Dashti A, Kadivar MR, Alborzi A, Sadeghi E, Pouladfar GR, Bagherian $\mathrm{N}$, Honar N, Khalifeh M. Analysis of hospital records of children with hydatid cyst in south of Iran. J Parasit Dis. 2017;41(4):1044-8.

29. Moldovan R, Neghina AM, Calma CL, Marincu I, Neghina R. Human cystic echinococcosis in two south-western and central-western Romanian counties: a 7-year epidemiological and clinical overview. Acta Trop. 2012; 121(1):26-9.

30. Kebede W, Hagos A, Girma Z, Lobago F. Echinococcosis/hydatidosis: its prevalence, economic and public health significance in Tigray region, North Ethiopia. Trop Anim Health Prod. 2009;41(6):865-71.

31. Farthing $M$, Jeffries $D$, Anderson J. Infectious diseases, tropical medicine and sexually transmitted diseases. Clin Med. 1994;4:96-7.

32. Dziri C. Hydatid disease-continuing serious public health problem: introduction. World J Surg. 2001;25(1):1-3.

33. Craig PS, Hegglin D, Lightowlers MW, Torgerson PR, Wang Q. Echinococcosis: control and prevention. Adv Parasitol. 2017:96:55-158.

\section{Publisher's Note}

Springer Nature remains neutral with regard to jurisdictional claims in published maps and institutional affiliations.

Ready to submit your research? Choose BMC and benefit from:
- fast, convenient online submission
- thorough peer review by experienced researchers in your field
- rapid publication on acceptance
- support for research data, including large and complex data types
- gold Open Access which fosters wider collaboration and increased citations
- maximum visibility for your research: over 100M website views per year
At BMC, research is always in progress.
Learn more biomedcentral.com/submissions

